\title{
MACHINING ACCURATE HOLES WITH REQUIRED ROUGHNESS
}

\author{
PAVEL DOSTAL, MAREK SADILEK, RADEK HRUBY \\ Faculty of Mechanical Engineering, Department of machining, \\ assembly and engineering metrology \\ VSB-TU Ostrava, Czech Republic \\ DOI: 10.17973/MMSJ.2019_10_201892 \\ Email: dostal.pa@email.cz
}

The knowledge gained from the theoretical and practical tests in the production of precise openings has been utilized in a wide range of technologies from simple machine parts to complex schemes requiring accurate placement of individual parts. The topic here deals with the production of precise holes of required roughness according to the customer's requirements, it is a sealing of hydraulic cubes with a ball plug. The article examines the possibilities of existing technology, proposes the possibilities of using other tools or changes in the machining parameters, all using one machine tool. All theoretical knowledge has been verified by practical tests with the use of measuring instruments such as hardness meters. All output measurements were recorded in tables and graphs for more clear results and used in practice.

\section{KEYWORDS}

Machining, tools, roughness, precise holes, machining parameters

\section{INTRODUCTION}

Nowadays, more and more emphasis is placed on the precision in the production of machine parts. Manufacture of precision parts affects other important aspects such as size, shape, or roughness. Roughness is the most important for determining the surface quality, it affects a number of properties such as wear, corrosion resistance, and notched toughness. Precision in production is different and depends on the type of product, chosen manufacturing technology or customer need. This article deals with the production of precision holes for the needs of hydraulic devices. Describes the current way with innovations.

\section{MACHINING OF INTERNAL SURFACES}

This technology can be divided into three basic types according to tool characteristics and cutting geometry. In terms of technology, the accuracy parameters and the roughness of the machined surfaces are important. Machining methods are divided into basic, abrasive and unconventional. The basic machining method is characterized by defined cutting edge geometry and the most important parameters are described in Table 1. [Kocman 2005]
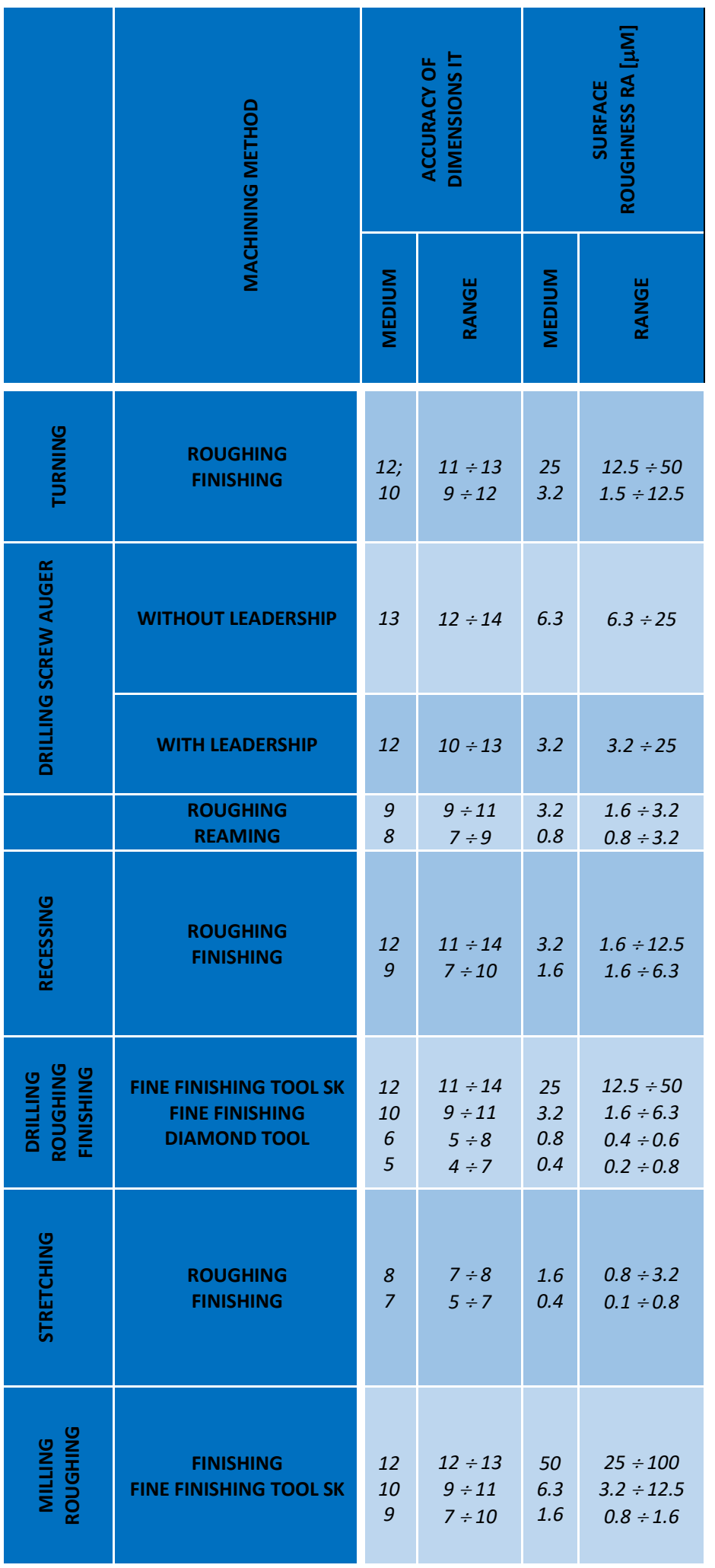

Table 1. Accuracy of machined surfaces [Kocman 2005]

Abrasive machining methods are characterized by undefined edge geometry, which is used in the production of machine parts with high demands on the quality of machined surfaces [Cep 2013]. 
Parameters of precision of machined surfaces are given in Table 2. [Kocman 2005]

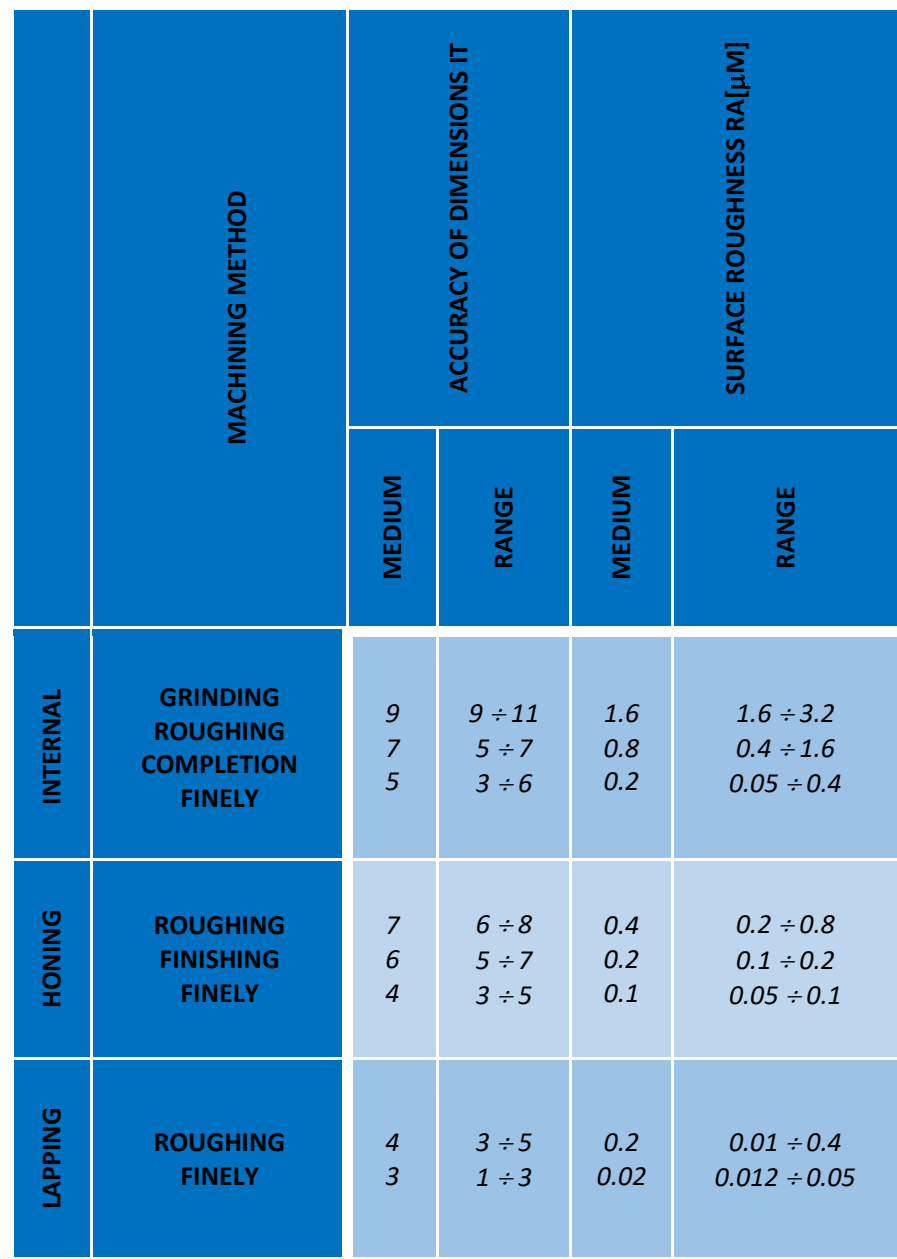

Table 2. Parameters of roughness of machined surfaces by abrasive method [Kocman 2005]

A qualitative parameter in production is the roughness of the surface, which is marked as the sum of the inequalities that occur during the machining of the material [Adamczak 2010]. In the case of a machined surface, the marks are created by the cutting tool. The size of these roughness depends on the physical and mechanical properties of the machined material, but also on the shape and geometry of the cutting edge [Mital 2018]. Other parameters that can be affected are feed rate, cutting speed, cutting environment, and rigidity of the machine assembly [Krolczyk 2013].

\section{PRODUCT DESCRIPTION AND EXISTING TECHNOLOGIES}

For the possibility of making a precise hole, a part of the hydraulic motor is used. It is a hydraulic cube used for mining machinery hydraulics. The article deals with part of the technology of production of this cube by producing a precision hole designed for a ball plug.
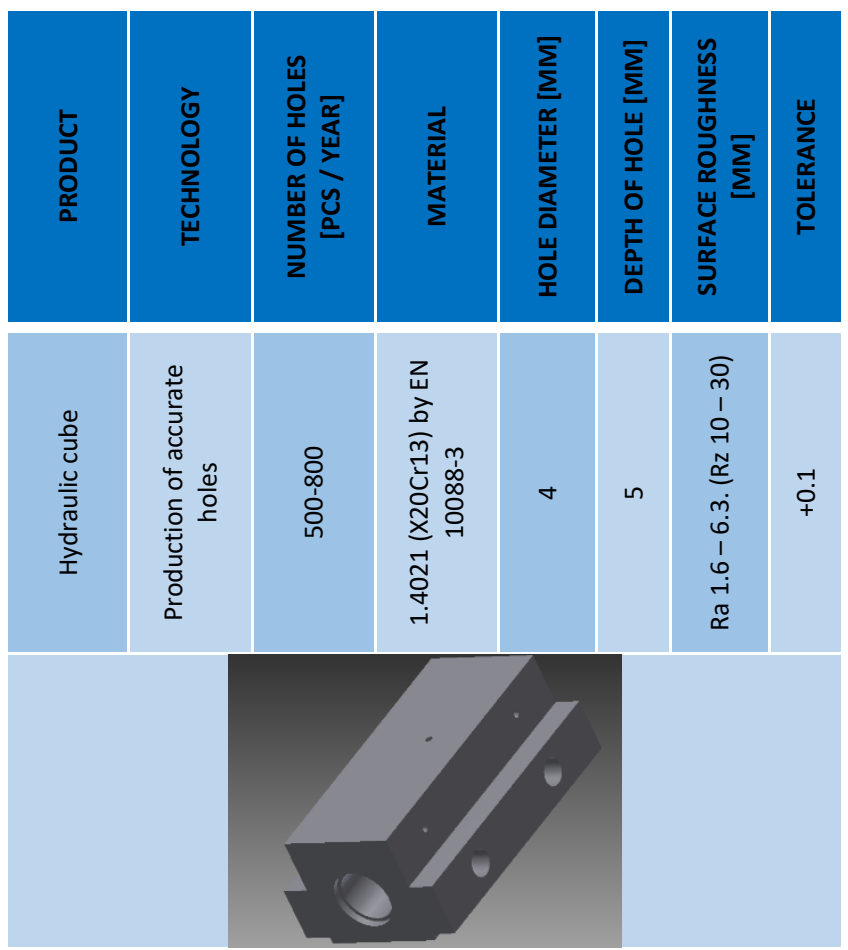

Table 3. Solved product design

In the first phase of making the required hole, it focused on existing production technology using machines and tools commonly used in production conditions. In the initial phase, the most logical way was to determine the holes first and to use the finishing method reamer. However, this method did not meet the required surface roughness for the assembly of other hydraulic components. Therefore, another option was chosen. The hole was first drilled with a $\varnothing 3 \mathrm{~mm}$ drill and then machined by a milling cutter with a roughing profile.

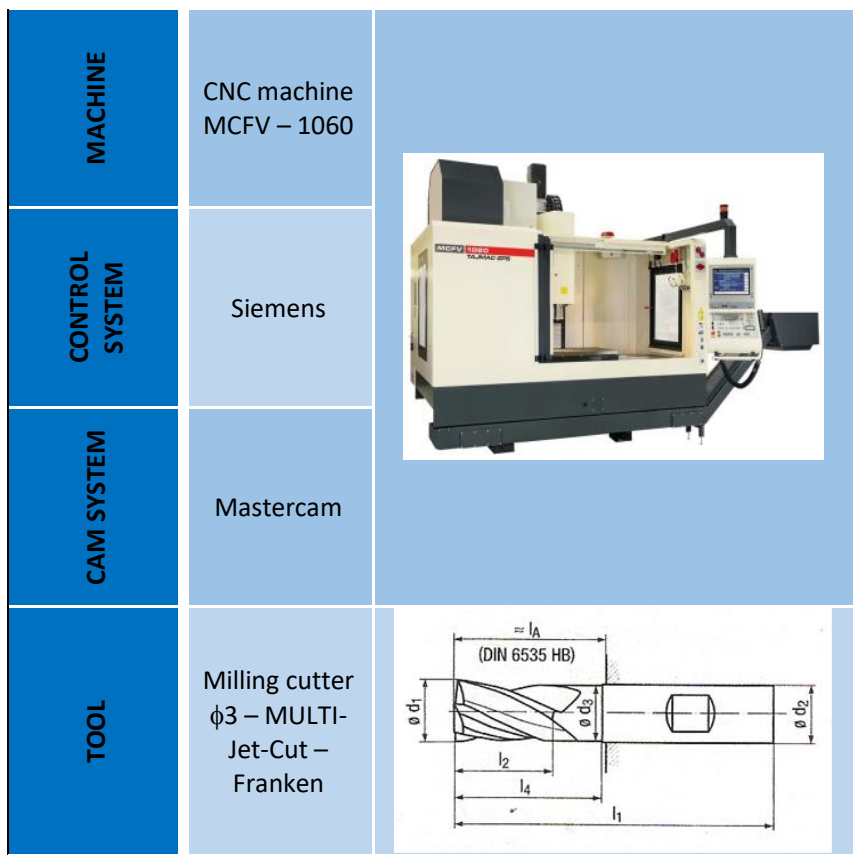



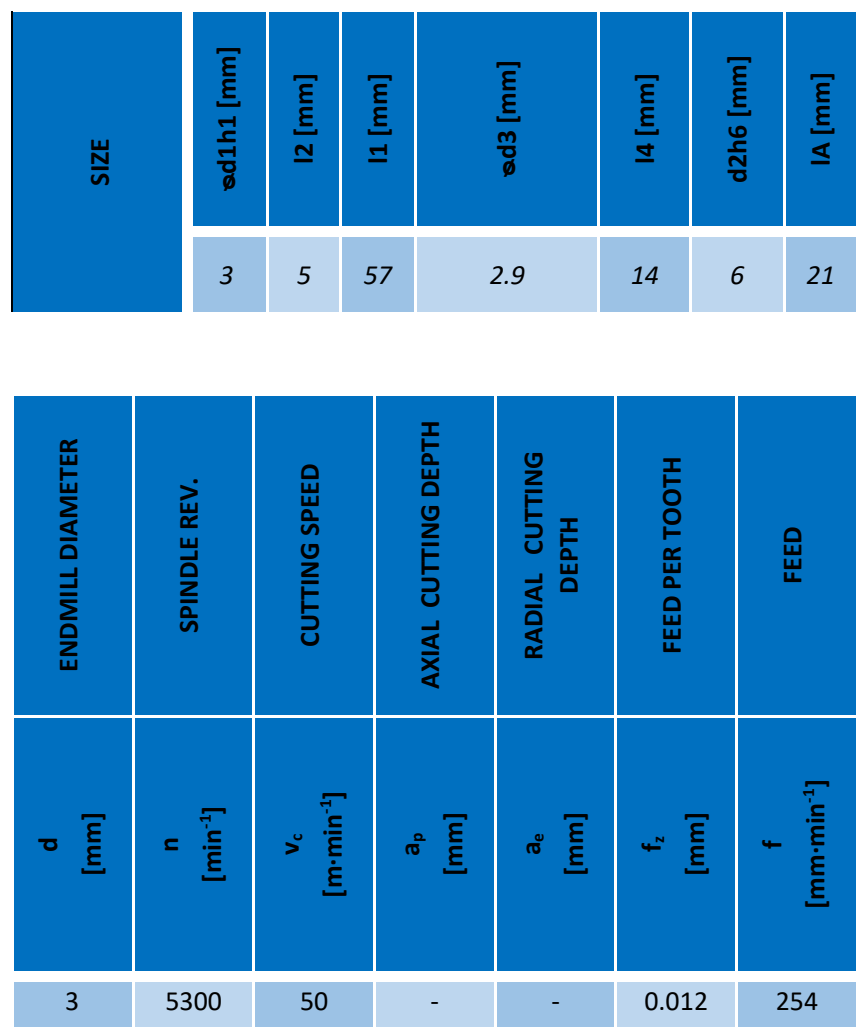

Table 4. Precision hole machine [Tajmac-zps 2012, Multicut 2012]

\section{CHOOSING THE ORIGINAL CUTTING TOOL}

In the initial phase of production, four holes were created using three tools (HSSCo - TITEX drill bit, Franken milling cutter) to determine the mean arithmetic deviation of the profile. The measurements were made using the MarSurS PS1 Portable Marsharm PS1 from the MAHR.

\begin{tabular}{|c|c|c|}
\hline TOOL & HOLE NUMBER & RA VALUE [MM] \\
\hline \multirow{2}{*}{ CUTTER FOR GROOVES } & 1. & 0.85 \\
\hline & 2. & 1.04 \\
\hline \multirow{2}{*}{ DRILL HSSCO TITEX } & 3. & 0.79 \\
\hline & 4. & 0.93 \\
\hline & 1. & 1.07 \\
\hline FRANKEN MILLING MACHINE & 2. & 1.37 \\
\hline & 3. & 1.21 \\
\hline & 4. & 1.15 \\
\hline & 2. & 6.23 \\
\hline & 3. & 6.27 \\
\hline
\end{tabular}

Table 5. Roughness of holes

\section{VARIANTS OF USABLE TOOLS}

There were several tools that met the necessary requirements and conditions for making holes. After the reamer rejection for too low roughness values, other options were selected after the cutting conditions were determined on the machined material (X20Cr13).

Variant I. There were used existing tools with changing cutting conditions for:

A) Carbide drill bit

B) Drill bit HSSCo - TITEX

C) Groove cutter

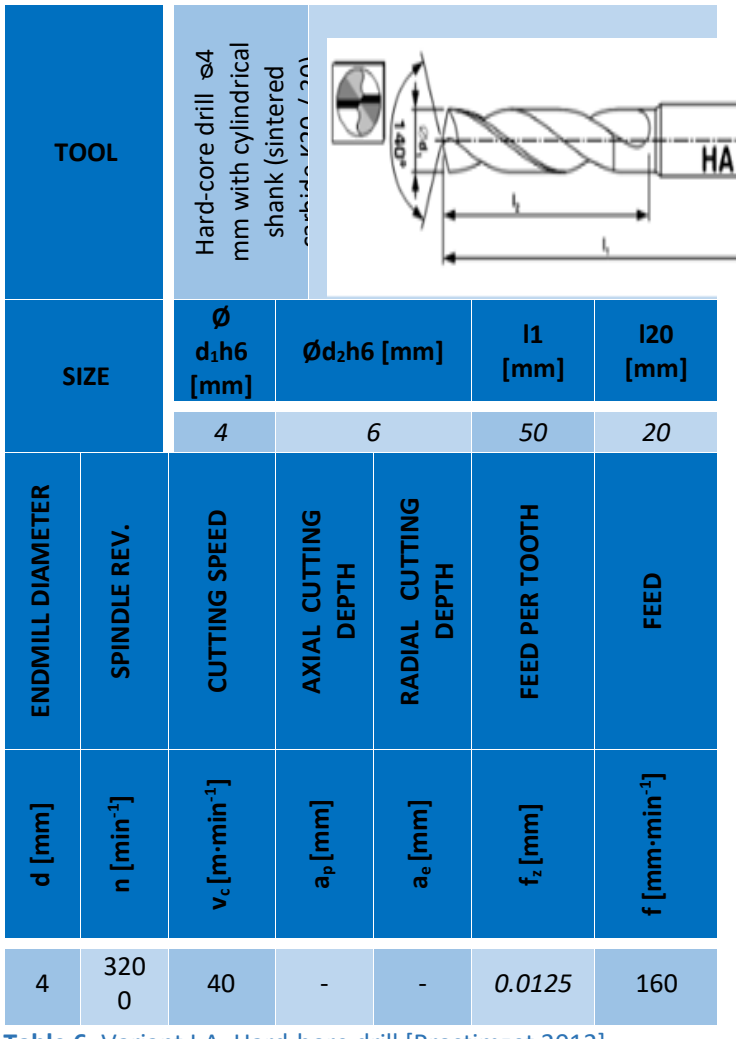

Table 6. Variant I.A. Hard-bore drill [Prostimzet 2012]



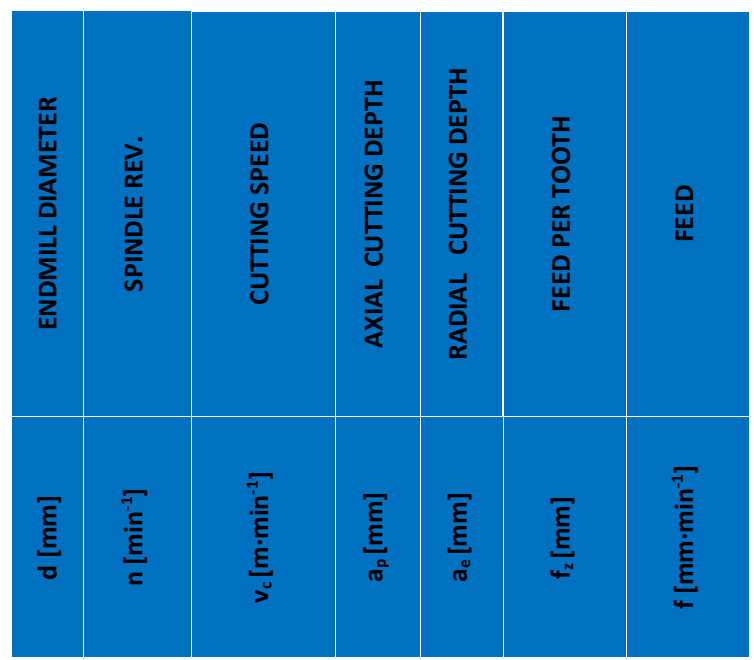
4
40
0.025
160

Table 7. Variant I.B. Drill HSSCo [Titex 2009]

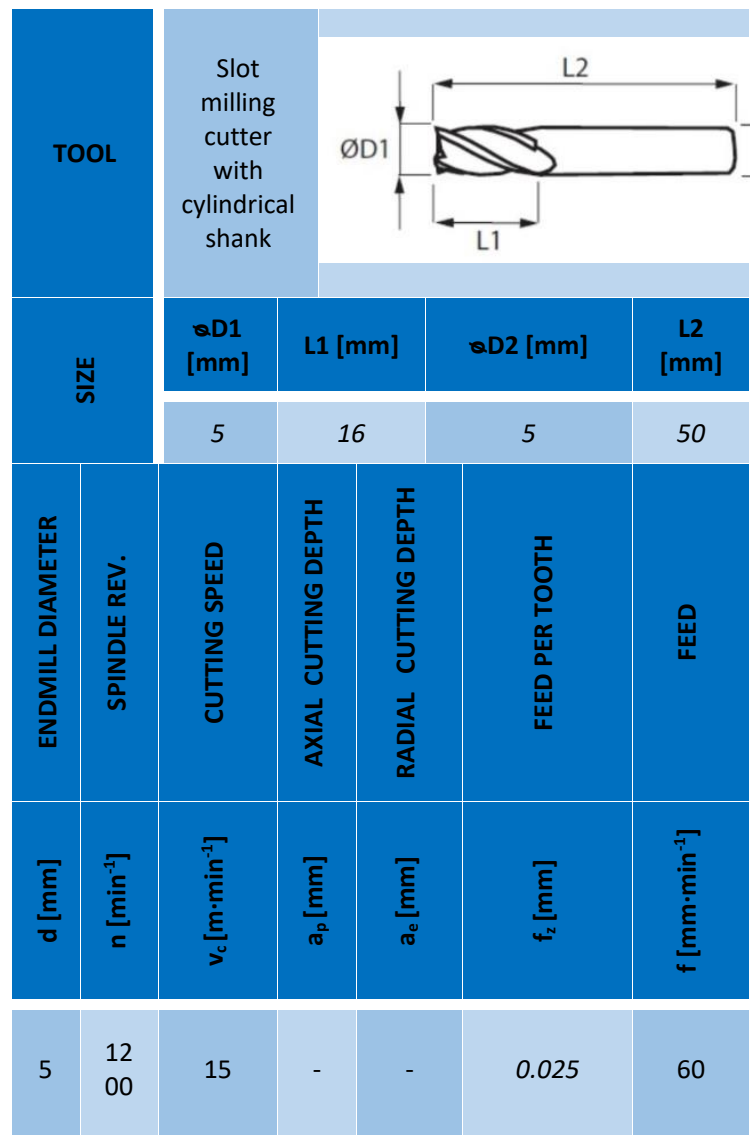

Table 8. Variant I.C. Slot milling cutter [Prostimzet 2004]

\section{VARIANT II.}

There was used an alternative tool: $4 \mathrm{~mm}$ diameter countersink, HSS 221605. The countershaft design is four-pronged with straight teeth with a cylindrical shank and guide pin.

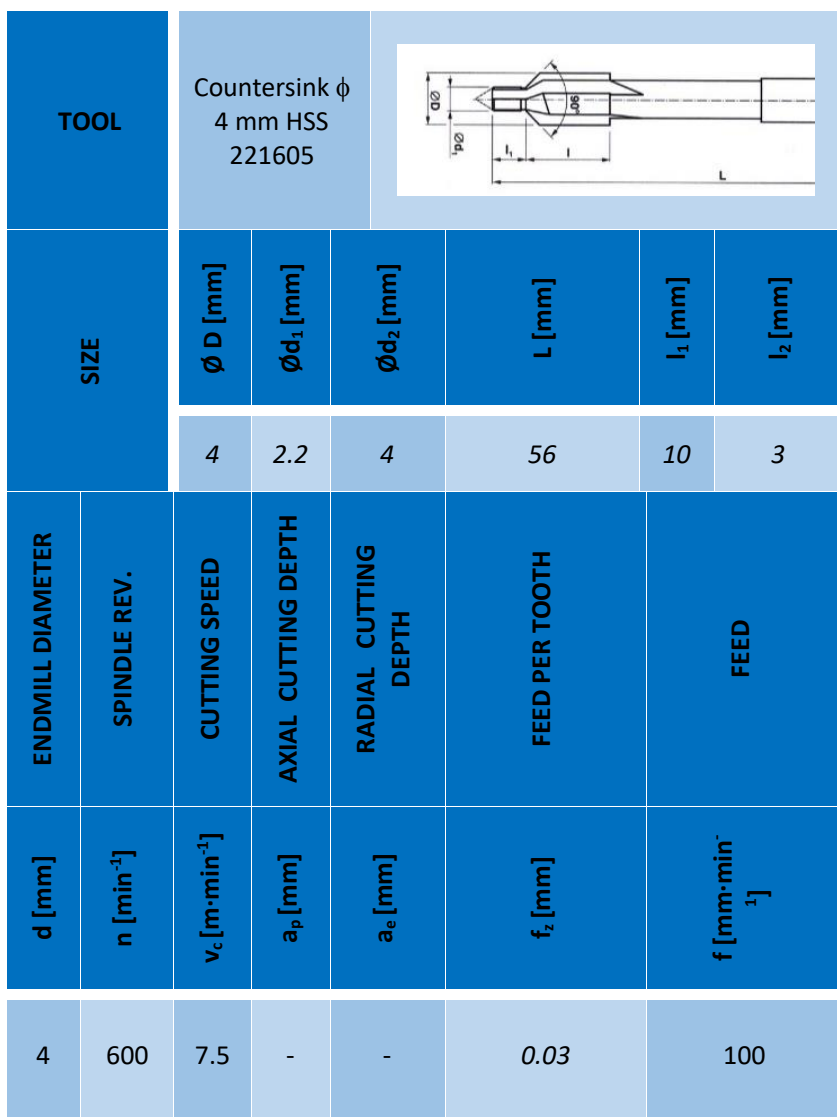

Table 9. Option II. Countersink [Mav 2012]

\section{MEASURING THE ROUGHNESS OF THE MACHINED SURFACE}

The following table shows the results of the mean arithmetic deflection of the profile Ra and the largest height of the profile Rz. With a constant cutting rate $v_{c}$, the feed rate $f_{z}$ being different for each opening, a five-count measurement was performed on each of the openings, and the arithmetic mean value was written to the table.

\begin{tabular}{|c|c|c|c|c|c|c|}
\hline 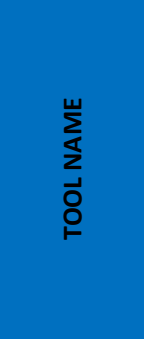 &  & 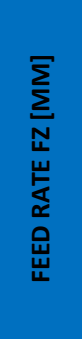 & 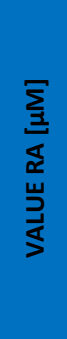 &  &  & 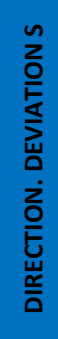 \\
\hline \multirow{4}{*}{ 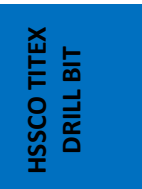 } & \multirow{4}{*}{40} & 0.025 & 1.38 & 0.01 & 8.53 & 0.18 \\
\hline & & 0.034 & 1.85 & 0.01 & 10.85 & 0.2 \\
\hline & & 0.044 & 1.97 & 0.19 & 11.57 & 0.64 \\
\hline & & 0.05 & 1.9 & 0.00 & 10.74 & 0.21 \\
\hline \multirow{4}{*}{ 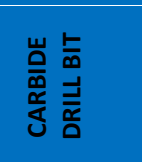 } & \multirow{4}{*}{40} & 0.013 & 1.04 & 0.01 & 7.14 & 0.24 \\
\hline & & 0.017 & 0.82 & 0.01 & 6.08 & 0.29 \\
\hline & & 0.022 & 0.86 & 0.01 & 7.32 & 0.24 \\
\hline & & 0.025 & 1.07 & 0.08 & 9.81 & 0.94 \\
\hline \multirow{3}{*}{ 웅 岁卢絮 } & \multirow{3}{*}{15} & 0.025 & 1.8 & 0.02 & 12.29 & 0.66 \\
\hline & & 0.033 & 3.01 & 0.04 & 18.21 & 0.42 \\
\hline & & 0.042 & 2.11 & 0.02 & 14.45 & 0.27 \\
\hline
\end{tabular}




\begin{tabular}{|c|c|c|c|c|c|c|}
\hline & & 0.05 & 2.84 & 0.09 & 14.57 & 0.94 \\
\hline \multirow{4}{*}{ 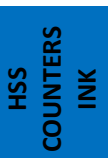 } & \multirow{4}{*}{7.5} & 0.025 & 2.97 & 0.02 & 16.29 & 1.08 \\
\hline & & 0.033 & 2.93 & 0.15 & 12.89 & 0.61 \\
\hline & & 0.042 & 1.52 & 0.02 & 13.68 & 0.38 \\
\hline & & 0.05 & 1.79 & 0.00 & 14.57 & 0.13 \\
\hline
\end{tabular}

Table 10. Measured roughness depending on machining parameters

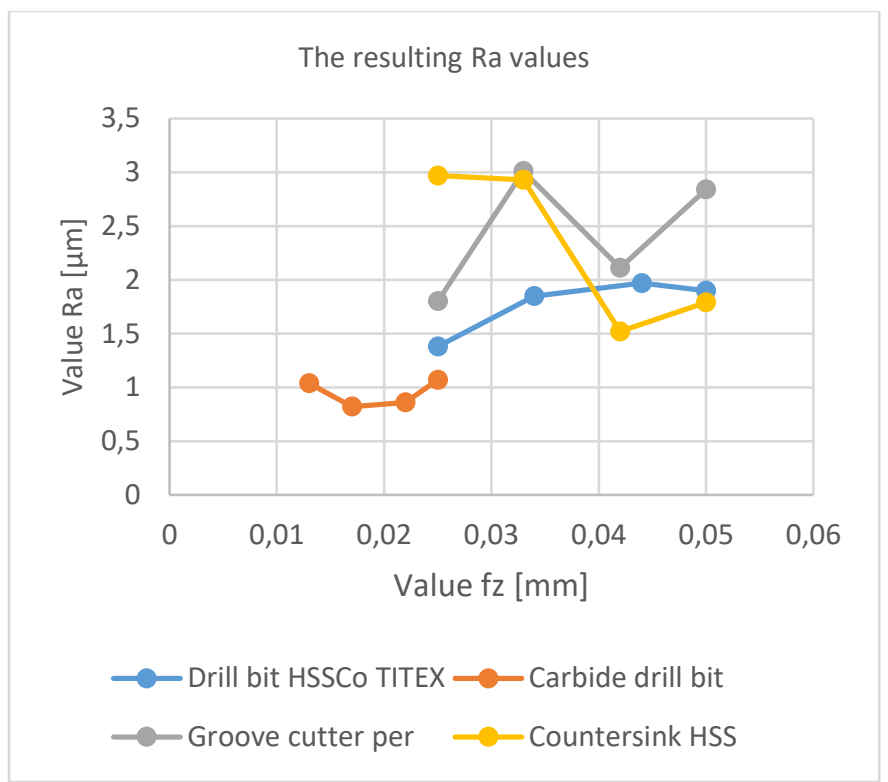

Figure 1. The resulting Ra values

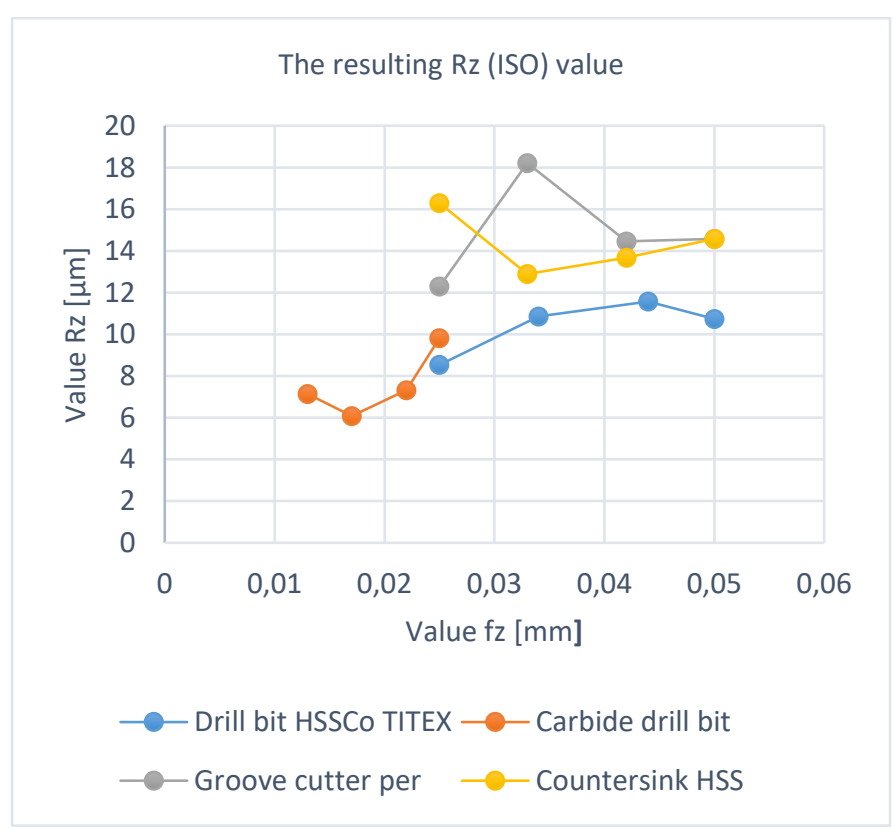

Figure 2. The resulting Rz (ISO) value

\section{CONCLUSION}

The production of precision holes can be made using several types of tools or different technologies. The initial design of the tool was complicated because the diameter of the machined hole was $\varnothing 4$ $\mathrm{mm}$. It was necessary to achieve higher surface roughness than normal. In such small openings, it is usually a requirement to achieve surface roughness parameters at much lower values.
The KOENIG Expander manufacturer recommends a surface roughness range in the range of $\mathrm{Rz} 10 \div 30[\mu \mathrm{m}]$ (when converted to $\mathrm{Ra}$ is csa 2.5 to $7.5 \mu \mathrm{m}$.) In view of the higher reliability of sealing of the hydraulic element, the surface roughness range $\mathrm{Ra} 3.2 \div 6.3$ [um].

An alternative tool (HSS Countersink) also investigated the possibility of using tools with other cutting conditions. On a measured subject whose material (X20Cr13) corresponds to the hydraulic cube in production, sixteen holes were used to measure roughness using four tools (HSSCo - TITEX drill, carbide drill, HSS groove cutter and HSS countersink). The values of $\mathrm{Ra}, \mathrm{Rz}$ at const. cutting speed $v_{c}$, but with rising $f_{z}$ values.

For both drill variants (HSSCo - TITEX drill bit, carbide drill bit), the required roughness values were not obtained even when the feed rate was increased. These tools are not suitable for making the mentioned holes. The groove cutter has achieved more favourable results. The measured values varied to the lower limit of the required surface roughness. (as with the HSS countersink). Subsequent increases in tool feed values are not appropriate for damage to tool destruction. The resulting damage would be uneconomical and would reduce the efficiency of work. The solution could be a change in cutting speed, an increase in speed. Results show that current technology achieves better results than an alternative tool that has been the subject of research.

Surface roughness is a very complicated matter and the resulting solution is not always unambiguous. The resulting roughness affects a large number of factors. In many cases, there is no other option than performing several tests and adjusting settings before finding a production method that is reliable, efficient, and economically acceptable.

\section{ACKNOWLEDGMENTS}

Article has been done in connection with projects Education system for personal resource of development and research in field of modern trend of surface engineering - surface integrity, reg. no. CZ.1.07/2.3.00/20.0037 financed by Structural Founds of Europe Union and from the means of state budget of the Czech Republic and by project Students Grant Competition SP2018/150 and SP2018/136 financed by the Ministry of Education, Youth and Sports and Faculty of Mechanical Engineering VŠB-TUO.

\section{REFERENCES}

[Adamczak 2010] Adamczak S. and Janecki D. and Stępień K. Qualitative and quantitative evaluation of the accuracy of the $\mathrm{V}$ block method of cylindricity measurements, Precision Engineering, vol. 34/3, 2010, pp. 619-626.

[Cep 2013] CEP, R. and JANASEK, A. and CEPOVA, L. and PETRU, J. and HLAVATY, I. and CAR, Z. and HATALA, M. Experimental testing of exchangeable cutting inserts cutting ability. Tehnički Vjestnik Technical Gazette, 2013. Vol. 20, No. 1, pp. 21-26. ISSN 1330-3651.

[Kocman 2005] KOCMAN, K. and PROKOP, J. MACHINERY TECHNOLOGY. 2nd Edition Brno: ACADEMIC NATIONAL CERM, 2005. ISBN 80-214-3068-0. 
[Krolczyk 2013] Krolczyk G. and Legutko S. and Gajek M. Predicting the surface roughness in the dry machining of duplex stainless steel (DSS), 2013, Metalurgija 52(2) 259-262.

[Mav 2012] Tool catalog: Counterbore and guide pin countersink. M \& V [online]. (c) 2004-2012 [cit. 2012-05-04]. Available from: http://katalog.mav.cz/detail.php?id=22617

[Minarcik 2012] MINARCIK, J. Preparation of the exact hole with the required roughness: bachelor thesis. Ostrava: VSB - Technical University of Ostrava, Faculty of Mechanical Engineering, Department of Machining and Assembly, 2012, 43 pp. Supervisor: Sadilek, M.

[Mital 2018] Mital, D. and Hatala, M. and Bernat, A. and Czan, A. and Vybostek, J. and Ungreanu, N. Dependence of surface roughness on depth of cut for aluminum alloy AlCu4Mg1. (2018) Manufacturing Technology, 18 (2), pp. 285-288. DOI: 10.21062/ujep/92.2018/a/1213-2489/MT/18/2/285.

[Multicut 2012] Multi-cut. emuge: high performance tools [online]. (C) 1999-2012 [cit. 2012-05-04]. Available from: http://www.emuge.com/multicut/

[Prostimzet 2004] Tool catalog: Tungsten carbide cutters. PROSTIMZET PLUS: production of tooling for holes [online]. (C) 2004-2012 [cit. 2012-05-04]. Available from: www.stimzetvsetin.cz/down/k frezy stopkove tvrdokov.pdf
[Prostimzet 2012] Tool catalog: Monolith SK drills. PROSTIMZET PLUS: production of tooling for holes [online]. (C) 2004-2012 [cit. 2012-05-04] Available from:

http://www.stimzetvsetin.cz/data/sk6537-3d en.html

[Tajmac-zps 2012] Tajmac-zps, mcfv 1060. TAJMAC-ZPS, a.s. [online]. Copyright (c) 2012 [cit. 2012-05-03]. Available from: http://www.tajmac-zps.cz/sites/tajmaczps2.0s.zps/files/mcfv1060 cz.pdf

[Titex 2009] Tool catalog. TITEX PLUS: precision machining tools [online]. [2009] [cit. 2012-05-04]. Available from: http://www.antee.cz/ckpchrudim/file.php?nid=1932\&oid=304380

\section{CONTACTS:}

Ing. Pavel Dostal

doc. Ing. Marek Sadilek, Ph.D.

Ing. Radek Hruby

VSB-TU Ostrava

Faculty of Mechanical Engineering

Department of machining, assembly and engineering metrology dostal.pa@email.cz; www.vsb.cz

marek.sadilek@vsb.cz; www.vsb.cz radek.hruby.st@vsb.cz; www.vsb.cz 